\title{
ANÁLISE DE IMAGEM APLICADA AO ESTUDO DO COMPORTAMENTO DE LEITÕES EM ABRIGO ESCAMOTEADOR
}

\author{
HÉLITON PANDORFI ${ }^{1}$, IRAN J. O. SILVA ${ }^{2}$, DANIELLA J. MOURA ${ }^{3}$, \\ KELLY B. SEVEGNANI ${ }^{4}$
}

\begin{abstract}
RESUMO: O objetivo geral desta pesquisa foi avaliar o comportamento de leitões em diferentes sistemas de aquecimento por meio da análise de imagem. A pesquisa foi desenvolvida na sala da maternidade, com 80 animais entre o nascimento e o desmame. Os tratamentos adotados para a avaliação da eficiência dos diferentes sistemas de aquecimento do abrigo escamoteador foram: piso térmico, lâmpada incandescente, resistência elétrica e lâmpada de infravermelho. Os dados ambientais foram registrados no ambiente externo, na sala da maternidade e no interior de cada abrigo escamoteador avaliado, ao longo de 19 dias. O delineamento experimental foi em blocos casualizados, com quatro tratamentos e 18 blocos, e as médias foram comparadas pelo teste de Tukey $(\mathrm{P}<0,01)$. Os valores médios de temperatura do bulbo seco apontam que o ambiente com piso térmico apresentou menor temperatura no microclima gerado, seguido da lâmpada incandescente, resistência elétrica e lâmpada de infravermelho, e que os três primeiros tratamentos atendem à condição de conforto recomendada aos leitões na maternidade. A avaliação comportamental utilizando a análise de imagem, indicou o piso térmico como o mais eficiente nas trocas de calor sensível por condução (contato), promovendo melhor condição de conforto aos animais.
\end{abstract}

PALAVRAS-CHAVE: comportamento animal, conforto térmico, suinocultura.

\section{ANALYSIS OF IMAGE APPLIED TO THE STUDY OF THE BEHAVIOUR OF PIGLETS IN THE CREEP}

SUMMARY: The objective of this research was to evaluate the behavior of piglets in different heating systems using the image analysis and geostatistics. This research was developed in a farrowing house, with 80 piglets between birth and weaning. The treatments were different heating systems: heat mat, standard heat lamp, electric resistance and infrared lamp. The climatic data were taken inside and outside the farrowing house and inside each studied creep, during two periods of 19 days long. The statistical design of the experiment was a randomized block with four treatments and 18 blocks. A Tukey test with $1 \%$ of probability was performed to compare the results averages. The average values of dry bulb temperature showed that the environment with heat mat presented a lesser temperature in the generated microclimate, followed by the standard heat lamp, electric resistance and infrared lamp. The three first treatments were recommended for better comforting for the piglets in the farrowing house. The behavior of the piglets was evaluated using the image analysis, and indicated that the best treatment was the heat mat as in the exchanges of sensible heat for conduction (contact), promoting better condition of comfort to the animals.

KEYWORDS: animal behavior, thermal comfort, swine production.

\footnotetext{
${ }^{1}$ Eng. Agrônomo, Pesquisador do Núcleo de Pesquisa em Ambiência, Doutorando do Curso de Física do Ambiente Agrícola, ESALQ/USP, Av. Pádua Dias, 11, Fone: (0XX19)3429.4217, R: 241, Piracicaba - SP, e-mail: hpandorf@esalq.usp.br.

${ }^{2}$ Eng. Agrícola, Prof. Doutor, Departamento de Engenharia Rural, NUPEA - ESALQ/USP, Piracicaba - SP.

${ }^{3}$ Eng ${ }^{\mathrm{a}}$. Agrônoma, Prof ${ }^{\mathrm{a}}$. Doutora, Departamento de Engenharia Rural, NUPEA - ESALQ/USP, Piracicaba - SP.

${ }^{4}$ Eng. Agrônomo, Pós-Doutoranda, Departamento de Engenharia Rural, NUPEA - ESALQ/USP, Piracicaba - SP.

Recebido pelo Conselho Editorial em: 2-6-2003

Aprovado pelo Conselho Editorial em: 17-5-2004
} 


\section{INTRODUÇÃO}

Na suinocultura, um dos maiores problemas relacionados ao conforto térmico e bem-estar animal está na maternidade, na qual se têm dois ambientes distintos a serem avaliados, com exigências bem diferenciadas. $\mathrm{Na}$ realidade, essa situação é um dos grandes problemas do produtor, pois em um pequeno espaço físico, há a necessidade de proporcionar dois microambientes diferentes e, caso isso não ocorra, os desempenhos das matrizes e dos leitões não serão satisfatórios.

Os animais exibem o nível de conforto térmico apresentando comportamentos distintos, ora amontoados, ora agrupados lado a lado ou esparsos. Esses são os padrões de postura dos leitões que se submetem ao frio, ao conforto e à sensação de calor, respectivamente (MOUNT, 1968).

A avaliação e os controles interativos do conforto térmico dos suínos pela análise de imagem superam os problemas inerentes ao método convencional de observação, pois utilizam os próprios animais como um biossensor em resposta aos reflexos do ambiente por meio do estudo comportamental (XIN \& SHAO, 2002).

Dessa forma, o esforço da pesquisa é desenvolver um sistema automatizado, em tempo real, pela análise de imagens, que execute a avaliação e o controle contínuo do conforto térmico dos suínos confinados, baseando-se em seus testes padrões de comportamento. O objetivo geral desta pesquisa consiste na avaliação do comportamento de leitões em diferentes sistemas de aquecimento nos abrigos escamoteadores, utilizando como ferramenta de avaliação a análise de imagem para o entendimento do comportamento animal.

\section{MATERIAL E MÉTODOS}

O desenvolvimento da pesquisa foi na sala da maternidade, no período compreendido entre o nascimento e o desmame dos leitões, com duração média de 19 dias, de acordo com o manejo adotado nessa produção.

Foi avaliada a eficiência de quatro sistemas de aquecimento nos abrigos escamoteadores, constituindo-se os seguintes tratamentos:

- Tratamento 1: abrigo escamoteador equipado com piso térmico de placas pré-moldadas de compósitos biomassa vegetal - cimento, aquecido por meio de resistência elétrica, confeccionadas no Laboratório de Ensaios de Materiais da Faculdade de Engenharia Agrícola da UNICAMP, com dimensões de 0,40 x 0,50 m, compondo um conjunto de três placas por abrigo (ROSSI et al., 2002).

- Tratamento 2: abrigo escamoteador equipado com lâmpada incandescente de $200 \mathrm{~W}$, fixada na parede de uma das extremidades do abrigo, a uma altura de $0,50 \mathrm{~m}$ do piso.

- Tratamento 3: abrigo escamoteador equipado com resistência elétrica de $200 \mathrm{~W}$, fixada na parede de uma das extremidades do abrigo, a uma altura de $0,50 \mathrm{~m}$ do piso.

- Tratamento 4: abrigo escamoteador equipado com lâmpada de infravermelho de $250 \mathrm{~W}$, fixada na parede de uma das extremidades do abrigo, a uma altura de $0,50 \mathrm{~m}$ do piso.

Os abrigos escamoteadores possuem dimensões de $1,50 \mathrm{~m}$ de comprimento por $0,55 \mathrm{~m}$ de largura, por 0,65 m de altura, totalizando uma área de $0,82 \mathrm{~m}^{2}$, e um volume de $0,53 \mathrm{~m}^{3}$. Em todos os tratamentos, a área de piso foi coberta por uma cama de maravalha, e os sistemas de aquecimento permaneceram acionados durante todo o período experimental (Figura 1).

Foram monitoradas as variáveis ambientais no abrigo escamoteador em oito celas parideiras avaliadas, na sala da maternidade e no ambiente externo. Foram registradas, por meio de sensores conectados a uma plataforma automática de coleta de dados, as seguintes variáveis: temperatura do bulbo seco (Ts), temperatura do bulbo úmido (Tu), temperatura do globo negro (Tg). 


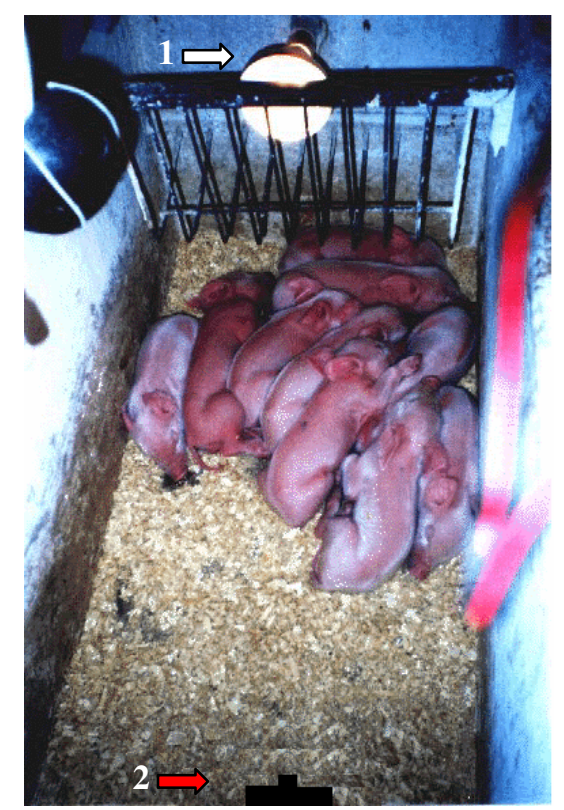

FIGURA 1. Abrigo escamoteador e posicionamento do sistema de aquecimento (1) e da microcâmera (2).

O registro dos dados de temperatura foi realizado em intervalos de 15 minutos, durante os 19 primeiros dias de vida dos leitões, período em que os animais permaneceram na maternidade. Os sensores para a obtenção da temperatura eram compostos por uma rede de cabos termopares do tipo T (cobre-constantan).

Nos abrigos escamoteadores, os sensores, para a determinação da $\mathrm{Ts}$, $\mathrm{Tu}$ e $\mathrm{Tg}$, foram acoplados na tampa dos abrigos escamoteadores, distando $0,55 \mathrm{~m}$ do piso. Na sala da maternidade, as variáveis ambientais foram registradas no interior da instalação, na região central das baias estudadas, a uma altura de 1,3 m do piso. Na área externa às instalações, os sensores foram instalados no interior de um abrigo meteorológico, a 1,5 m de altura da superfície, representando o microclima do local.

O ponto fundamental desta pesquisa é justamente a avaliação dos sistemas de aquecimento, usando a análise comportamental dos animais para a compreensão da eficiência do sistema, em função da sensação do conforto animal. Portanto, utilizou-se, como ferramenta para registro desses dados, a análise de imagem, por meio de microcâmeras instaladas no interior de cada abrigo escamoteador. Foram utilizadas microcâmeras preto e branco com lente de $2,45 \mathrm{~mm}$ e leds de infravermelho, o que permitiu obter as imagens nos abrigos onde não havia fontes de luz, no caso daqueles equipados com piso térmico e resistência elétrica. As imagens registradas foram analisadas com o objetivo de verificar a frequiência de uso e o tempo de permanência dos animais no abrigo, permitindo verificar a descrição do comportamento dos animais dentro do abrigo, em função dos sistemas de aquecimento e das variáveis ambientais envolvidas no estudo. $\mathrm{O}$ registro e o armazenamento das imagens foram realizados diariamente em intervalos de 2 minutos, sendo gerenciados pelo software "VIDEOCAP", armazenando as informações num banco de dados para posterior análise.

A análise das imagens foi realizada para três dias críticos, considerados nesta pesquisa como os dias de menor entalpia do período, segundo MOURA et al. (1997). Deve-se considerar que, por se tratar de aquecimento, adotou-se a menor entalpia como crítica, por considerar a menor quantidade de calor presente em uma parcela de ar seco, de acordo com a equação proposta por ALBRIGHT (1990):

$$
\mathrm{H}=1,006 \mathrm{Ts}+\mathrm{W}(2501+1,805 \mathrm{Ts})
$$


em que,

$\mathrm{H}$ - entalpia, $\mathrm{kJ} \mathrm{kg}$ ar $\mathrm{seco}^{-1}$;

Ts - temperatura do bulbo seco, ${ }^{\circ} \mathrm{C}$;

$\mathrm{W}$ - razão de mistura, $\mathrm{kg}$ vapor d'água $\mathrm{kg}$ ar $\mathrm{seco}^{-1}$.

Além das variáveis ambientais, foram também registradas as variações de temperatura do piso de todos os abrigos escamoteadores envolvidos no estudo, visando à identificação da variação espacial da temperatura na área do abrigo, em relação às diferentes fontes de aquecimento. $\mathrm{O}$ registro dos dados foi realizado manualmente, em intervalos de $4 \mathrm{~h}$, no período das 8 às $20 \mathrm{~h}$, totalizando quatro observações diárias. A representação das isotermas foi realizada por meio do software "SURFER".

O registro da temperatura do piso foi realizado em nove pontos, de acordo com a representação esquemática da Figura 2.

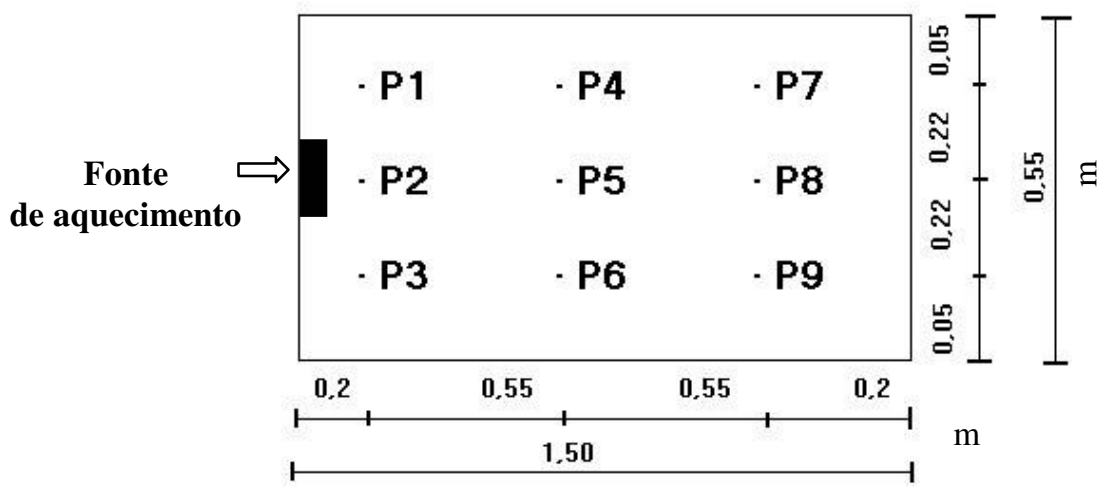

FIGURA 2. Representação dos pontos de medida de temperatura do piso nos abrigos escamoteadores.

Foi utilizado o delineamento em blocos casualizados (DBC), adotando-se quatro tratamentos e 18 blocos. Pelo fato de não se trabalhar com repetições, consideraram-se os blocos como o número de observação diária (18 dias) estudado no experimento (Tabela 1). As médias das variáveis-resposta dos microambientes foram comparadas pelo teste de Tukey $(\mathrm{P}<0,05)$. Toda a análise estatística foi realizada por meio do programa estatístico Statistical Analysis System (SAS, 1992).

TABELA 1. Análise da variância utilizada na pesquisa.

\begin{tabular}{cc}
\hline C.V. & G.L. \\
\hline Blocos & 17 \\
Tratamentos & 3 \\
Resíduo & 51 \\
Total & 71 \\
\hline
\end{tabular}

\section{RESULTADOS E DISCUSSÃO}

A determinação da temperatura no ambiente em que os animais foram expostos é de fundamental importância para o entendimento do comportamento e distribuição dos animais no abrigo escamoteador. A comparação entre tratamentos, apresentada na Tabela 2, é o resultado médio diário das variáveis-resposta dos microambientes estudados, abrigos escamoteadores e seus respectivos sistemas de aquecimento. Verificou-se que todos os tratamentos apresentaram diferenças significativas para a temperatura do bulbo seco (Ts), temperatura do globo negro (Tg), umidade relativa (UR) e entalpia $(\mathrm{H})$. 
A temperatura do bulbo seco apresentou uma variação significativa entre os quatro tratamentos estudados. Por meio de valores médios, pode-se verificar que o ambiente com piso térmico apresentou menor temperatura no microclima gerado, seguido da lâmpada incandescente, resistência elétrica e lâmpada de infravermelho, respectivamente. De forma geral, pode-se dizer que, para a zona de conforto térmico para os leitões na fase da maternidade, os três primeiros tratamentos são recomendados, porém deve-se lembrar que esses dados são valores médios diários.

TABELA 2. Valores médios das variáveis ambientais observadas durante a permanência dos leitões na maternidade.

\begin{tabular}{lcccc}
\hline Tratamentos & Ts & Tg & UR & H \\
& $\left({ }^{\circ} \mathrm{C}\right)$ & $(\%)$ & $60,5 \mathrm{a}$ & $68,9 \mathrm{~d}$ \\
\hline Piso térmico & $28,7 \mathrm{~d}$ & $28,9 \mathrm{c}$ & $48,9 \mathrm{~b}$ & $72,1 \mathrm{c}$ \\
Lâmpada incandescente & $32,2 \mathrm{c}$ & $32,8 \mathrm{~b}$ & $50,6 \mathrm{c}$ & $75,9 \mathrm{~b}$ \\
Resistência elétrica & $32,9 \mathrm{~b}$ & $32,9 \mathrm{~b}$ & $31,7 \mathrm{~d}$ & $81,1 \mathrm{a}$ \\
Lâmpada de infravermelho & $40,4 \mathrm{a}$ & $41,8 \mathrm{a}$ & $\left.\mathrm{C}^{\circ}\right)$ & \\
\hline
\end{tabular}

Valores médios com letras diferentes, na mesma coluna, diferem pelo teste de Tukey $(\mathrm{P}<0,05)$.

Na Figura 3, apresenta-se a influência do efeito dos diferentes sistemas de aquecimento na temperatura interna dos abrigos escamoteadores. Nessas condições, verifica-se que o aquecimento proporcionado aos leitões pela lâmpada incandescente e resistência elétrica foi o que mais se aproximou da faixa de conforto térmico dos animais, 32 a $28{ }^{\circ} \mathrm{C}$ (SILVA, 1999). O tratamento piso térmico esteve abaixo da condição recomendada, principalmente na primeira semana de vida dos animais.

Com relação à lâmpada de infravermelho, os dados referentes à temperatura no interior do abrigo estiveram, em média, sempre acima da condição ideal durante toda a fase experimental, ultrapassando o valor da temperatura crítica superior (TCS) de 38 a $33{ }^{\circ} \mathrm{C}$ (MOUNT, 1968; CURTIS, 1983).
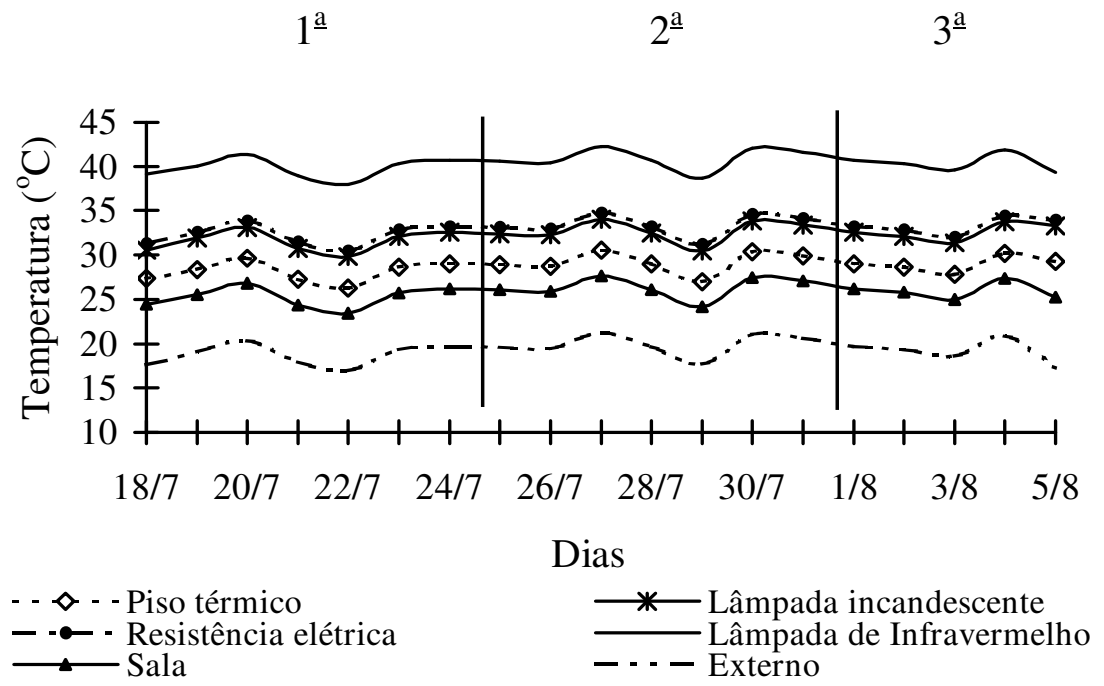

FIGURA 3. Variação da temperatura média diária nos diferentes tratamentos, na sala da maternidade e no abrigo meteorológico (ambiente externo).

Com a intenção de validar as informações obtidas, pela variação da temperatura média diária, nos tratamentos avaliados, observa-se na Figura 4 a variação das temperaturas mínimas diárias. Esses resultados demonstraram que a condição de conforto, na primeira e segunda semanas de vida dos animais, foi atendida pelos tratamentos lâmpada incandescente e resistência elétrica. Para o tratamento 
piso térmico, a disponibilidade de energia térmica, proporcionada pela fonte de aquecimento, não foi suficiente para as duas semanas iniciais, contemplando as exigências dos animais apenas na terceira semana.

O tratamento com lâmpada de infravermelho apresentou, praticamente, a mesma resposta, mostrando-se sempre acima da condição adequada, atingindo valores de TCS de $38{ }^{\circ} \mathrm{C}$.
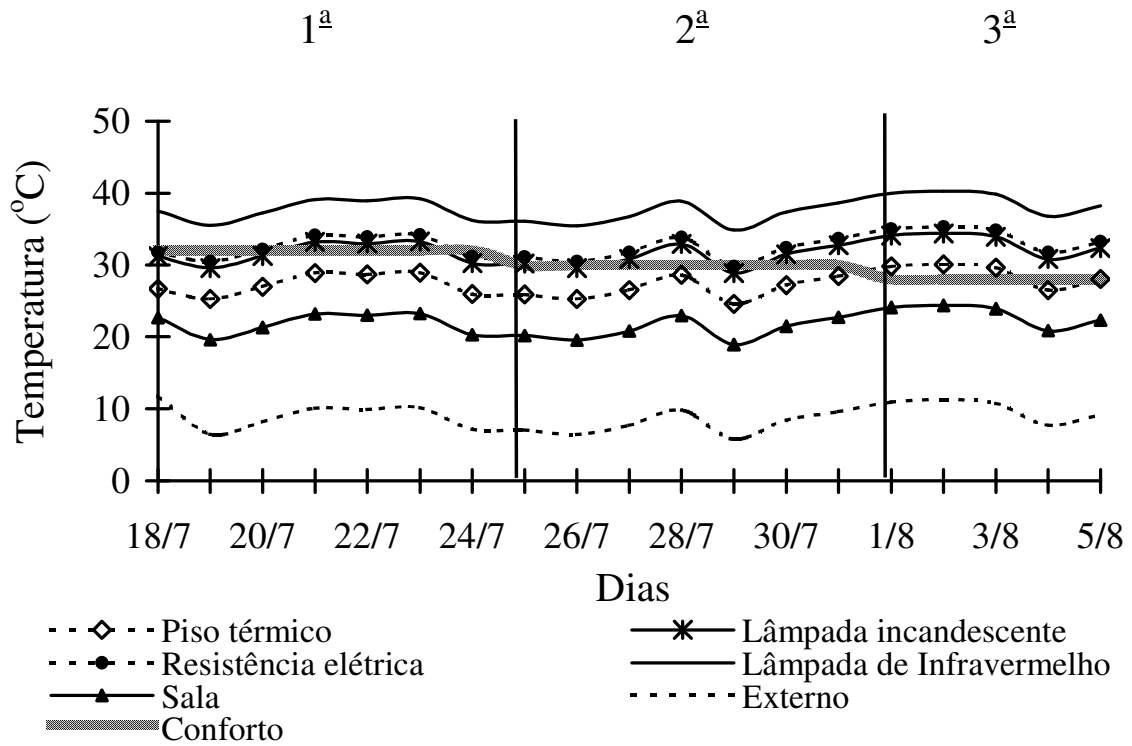

FIGURA 4. Variação da temperatura mínima diária nos diferentes tratamentos, na sala da maternidade e no abrigo meteorológico (ambiente externo).

Os sistemas de aquecimento mais adequados, mesmo para os dias selecionados, dias de menor entalpia, foram lâmpada incandescente e resistência elétrica (Figura 5). Para os outros tratamentos, a temperatura apresentou-se acima (lâmpada de infravermelho) e abaixo (piso térmico) das condições de conforto térmico dos leitões, 32 a $28{ }^{\circ} \mathrm{C}$ (SILVA, 1999).

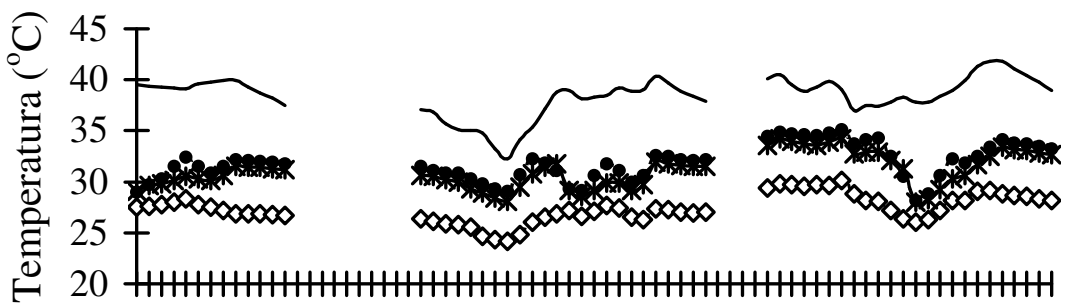

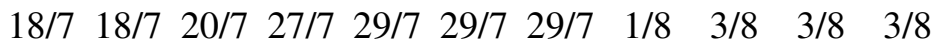

Dias
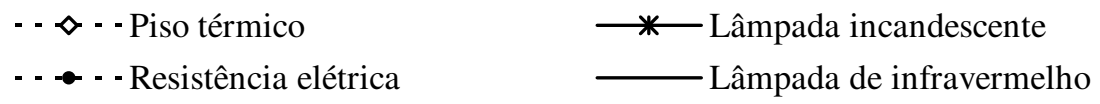

FIGURA 5. Variação da temperatura para os dias de menor entalpia nos diferentes tratamentos avaliados.

Com relação aos dados referentes à temperatura do globo negro, os valores registrados para os diferentes sistemas de aquecimento estudados apresentaram o mesmo comportamento da Ts, devido à pequena variação apresentada entre as respectivas variáveis ambientais. 
Os valores médios da entalpia $(\mathrm{H})$ apresentaram resultados que apontam diferenças estatísticas entre todos os tratamentos. O maior valor verificado foi para o abrigo equipado com lâmpada de infravermelho, resistência elétrica, lâmpada incandescente e piso térmico, respectivamente, expressando a quantidade de energia interna da parcela de ar, nos microambientes avaliados, em relação à soma de suas componentes, de uma mistura de ar seco e vapor d'água, levando-se em consideração a Ts $\left({ }^{\circ} \mathrm{C}\right)$ e a razão de mistura (kg de vapor d'água/kg de ar seco).

Pode-se verificar, na Figura 6, que a variação entálpica nos tratamentos adotados, para a primeira semana experimental, não atingiu o valor ideal de $90,2 \mathrm{~kJ} / \mathrm{kg}$ ar seco, em nenhum dos tratamentos avaliados, sendo que o sistema de aquecimento que mais se aproximou do valor recomendado, foi a lâmpada de infravermelho. Para a segunda semana, o tratamento mais eficiente foi a resistência elétrica, que apresentou valores mais próximos de $81,6 \mathrm{~kJ} / \mathrm{kg}$ ar seco. $\mathrm{Na}$ última semana, os tratamentos lâmpada incandescente e resistência elétrica foram aqueles que melhor se ajustaram à condição ideal, de $73,8 \mathrm{~kJ} / \mathrm{kg}$ ar seco; o piso térmico esteve sempre abaixo da condição entálpica necessária ao conforto dos leitões.

Os valores de entalpia recomendados para os animais foram calculados com base nas condições de conforto dos animais, 32; 30 e $28^{\circ} \mathrm{C}$, e umidade relativa de $70 \%$, citadas por SILVA (1999), para a primeira, segunda e terceira semanas de vida dos leitões, respectivamente.
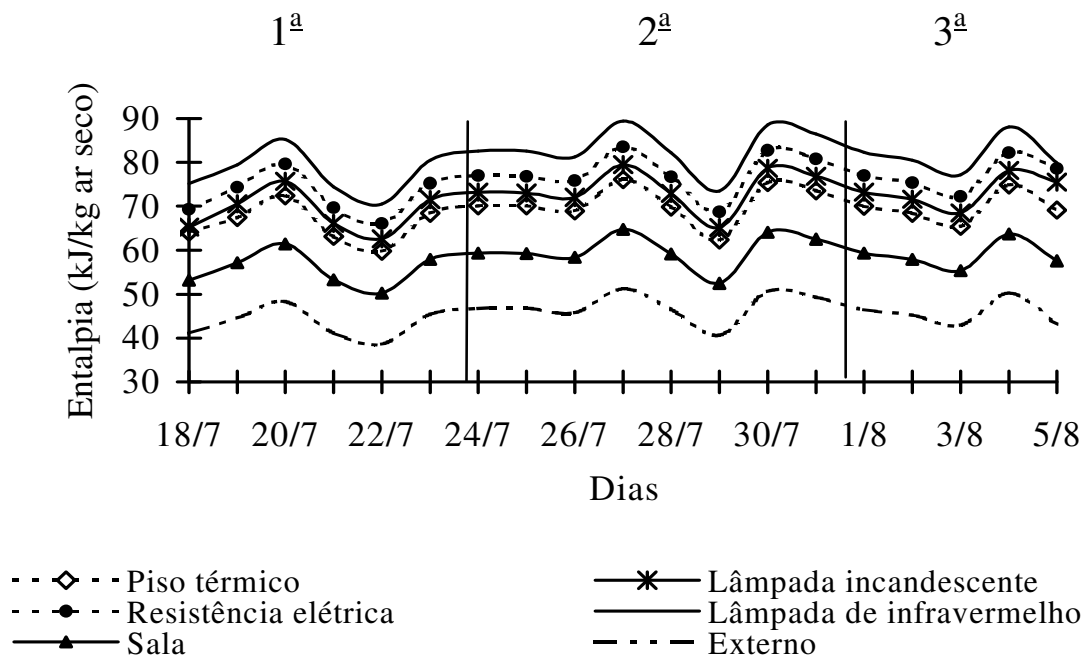

FIGURA 6. Variação da entalpia média diária nos diferentes tratamentos, na sala da maternidade e no abrigo meteorológico (ambiente externo).

Para certificar-se das informações citadas acima, procurou-se representar as variações mínimas de entalpia verificadas nessa fase, como se pode observar na Figura 7. Considerando-se as condições mínimas de entalpia, foi procedido o cálculo dessa grandeza psicrométrica, utilizando-se da temperatura mínima diária.

Considerando-se a quantidade de calor existente na massa de ar seco dentro de cada abrigo escamoteador, pode-se dizer, pelos dados apresentados na Figura 7, que nenhum dos tratamentos estudados foi eficiente no acondicionamento dos animais, durante as duas primeiras semanas críticas de vida dos leitões; porém, para a terceira semana, os sistemas de aquecimento lâmpada incandescente, resistência elétrica e lâmpada de infravermelho atenderam efetivamente à condição de conforto dos animais. 


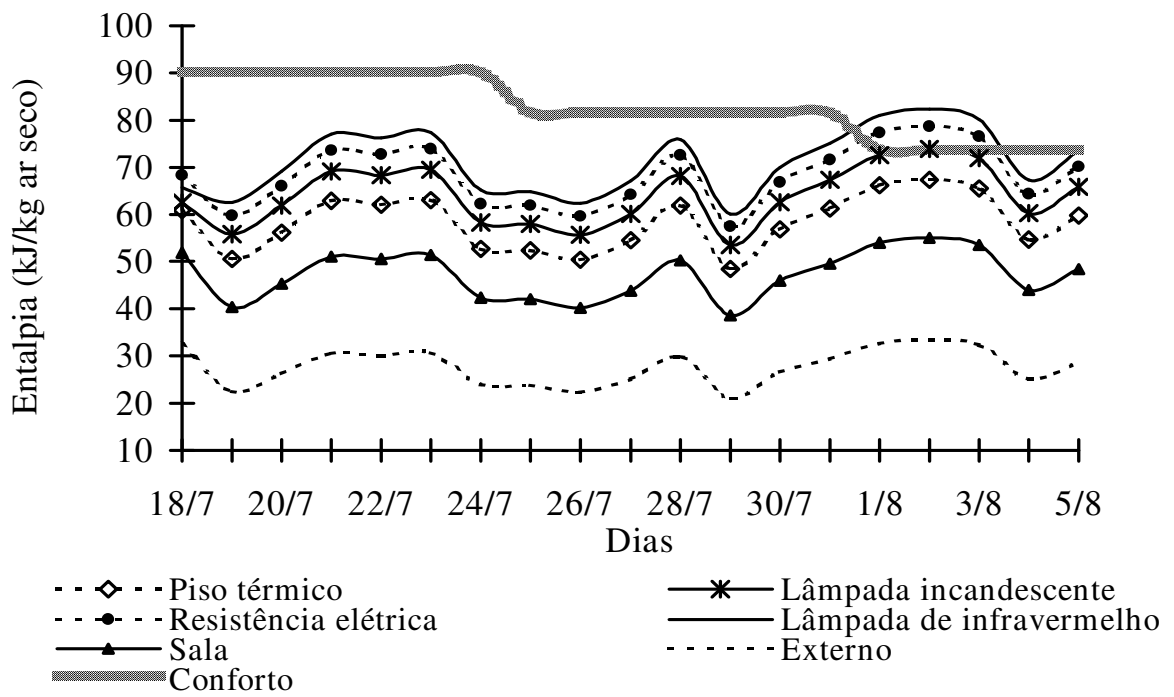

FIGURA 7. Variação da entalpia mínima diária nos diferentes tratamentos, na sala da maternidade e no abrigo meteorológico (ambiente externo).

Em função das imagens geradas pelas microcâmeras de vídeo e da identificação do posicionamento de cada animal no microambiente, associou-se o posicionamento dos animais com o perfil de distribuição da temperatura no piso de cada abrigo estudado. Dessa forma, a análise foi realizada para o dia crítico do período (3-8-2002) considerado o mais frio, para os horários de maior e menor temperatura nesse dia, de acordo com os dados apresentados na Tabela 3.

TABELA 3. Valores horários de temperatura no interior da sala da maternidade, para o dia crítico (3-8-2002).

\begin{tabular}{cccc}
\hline Horário & Temperatura $\left({ }^{\circ} \mathrm{C}\right)$ & Horário & Temperatura $\left({ }^{\circ} \mathrm{C}\right)$ \\
\hline $8 \mathrm{~h}$ & 24,7 & $15 \mathrm{~h}$ & 25,4 \\
$9 \mathrm{~h}$ & 24,8 & $16 \mathrm{~h}$ & 25,5 \\
$10 \mathrm{~h}$ & 24,8 & $17 \mathrm{~h}$ & 25,4 \\
$11 \mathrm{~h}$ & 25,0 & $18 \mathrm{~h}$ & 25,4 \\
$12 \mathrm{~h}$ & 25,1 & $19 \mathrm{~h}$ & 25,1 \\
$13 \mathrm{~h}$ & 25,1 & $20 \mathrm{~h}$ & 24,9 \\
$14 \mathrm{~h}$ & 25,2 & & \\
\hline
\end{tabular}

Nas Figuras 8 (a) e 9 (a), são apresentadas as imagens gravadas pela microcâmera, no abrigo equipado com piso térmico, nos horários das 8 e 16 horas, em que se observou a distribuição dos animais no abrigo. Nas Figuras 8 (b) e 9 (b), mostra-se o resultado do comportamento dos animais em função da temperatura do piso, em que se observaram as isotermas no abrigo.

De acordo com a Figura 8 (b), notou-se que, no horário mais frio do dia (8 horas), a disposição dos animais está na região onde a faixa da temperatura do piso é maior, nesse caso, entre 29,7 e $30,7^{\circ} \mathrm{C}$. Da mesma forma, observou-se que, no horário em que a temperatura foi maior (16 horas), a distribuição dos leitões foi diferenciada ao longo dos perfis das isotermas no piso, ou seja, $71 \%$ dos animais presentes no abrigo permaneceram na faixa de temperatura entre 29,6 e $30,6{ }^{\circ} \mathrm{C}$, e $29 \%$ na região onde a temperatura do piso era em torno de $28{ }^{\circ} \mathrm{C}$ (Figura $9 \mathrm{~b}$ ).

Esses efeitos podem ser explicados pela eficiência condutiva do piso térmico e pela exigência térmica dos animais, considerando-se que a análise foi realizada na terceira semana de vida dos 
animais. Verifica-se, também, a eficiência do sistema de aquecimento, relacionado à variação espacial da temperatura ao longo do piso do abrigo escamoteador e o perfil de distribuição dos animais.

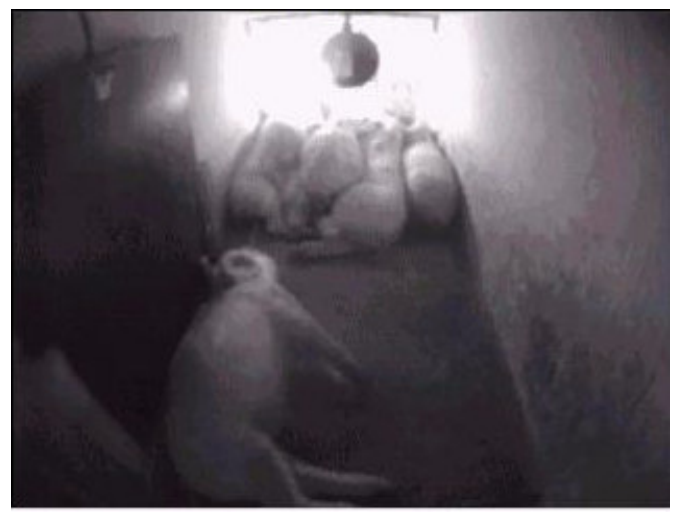

(a)

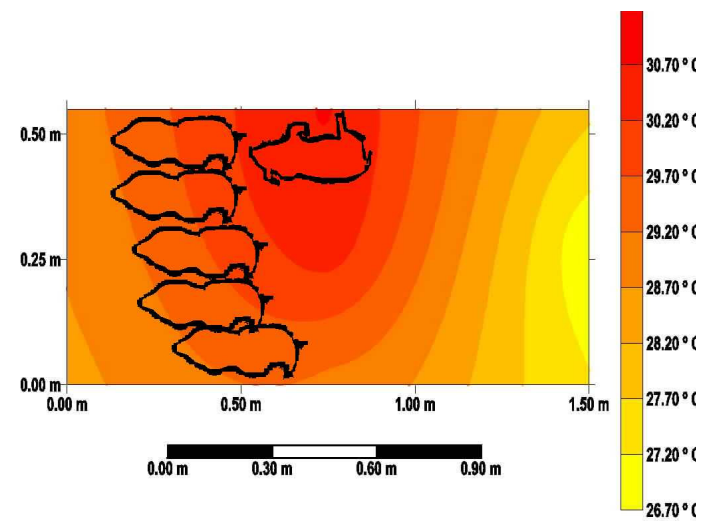

(b)

FIGURA 8. Imagem captada (a) e representação das isotermas (b) representando o perfil de distribuição dos animais, para o abrigo equipado com piso térmico, para as 8 horas.

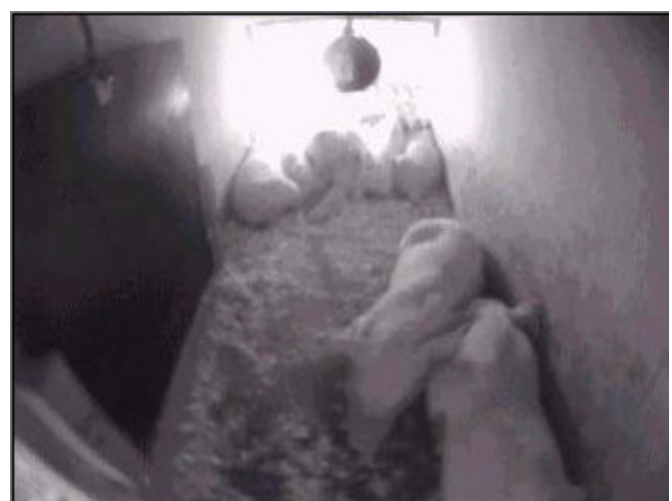

(a)

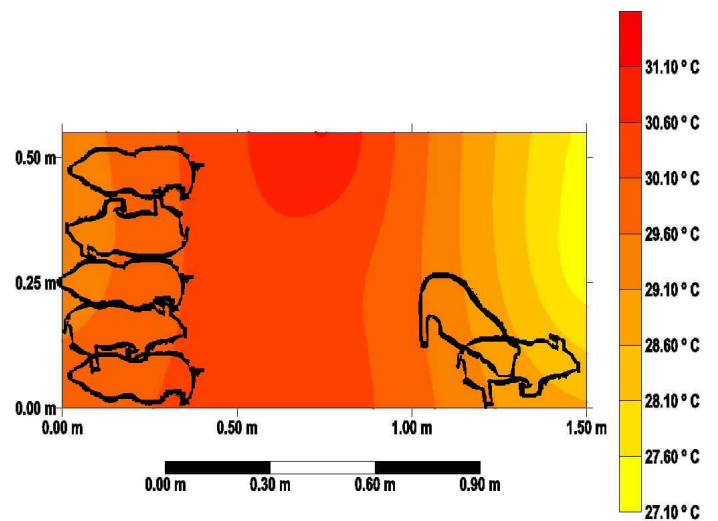

(b)

FIGURA 9. Imagem captada (a) e representação das isotermas (b) representando o perfil de distribuição dos animais, para o abrigo equipado com piso térmico, para as 16 horas.

Comparando-se os abrigos com lâmpada incandescente e resistência elétrica, verificou-se que a variação espacial da temperatura foi reduzida, à medida que se afastou da fonte de aquecimento (Figuras 10 b, 11 b).

Essa tendência também foi observada no piso do abrigo com lâmpada de infravermelho, porém observou-se que as temperaturas no piso foram inferiores às ideais requeridas. Diante disso, sabe-se que o processo convectivo foi alterado em função da movimentação do ar no interior do escamoteador, o que pode influenciar na distribuição das isotermas no mesmo.

Pode-se observar que a distribuição da temperatura no abrigo com piso térmico foi mais uniforme, o que confirma os resultados apresentados anteriormente. Referindo-se ao perfil de distribuição dos leitões no interior dos abrigos, verifica-se, em geral, que, para todos os tratamentos avaliados, os animais apresentaram a tendência de buscar pontos mais próximos da fonte de calor, ou as faixas de maior temperatura, no horário das 8 horas, sendo que, para o horário das 16 horas, o padrão de distribuição se inverteu, ou seja, os animais buscaram regiões do piso que apresentavam faixas de menor temperatura e mais distantes da fonte de calor. 
Nesse contexto, a associação das variáveis ambientais estudadas - temperatura, umidade e avaliação comportamental - confirma e valida os resultados da análise de imagem aplicada no entendimento bioclimático dos leitões, apontando o piso térmico como o mais eficiente nas trocas de calor sensível por condução (contato), promovendo melhor condição de conforto aos animais.

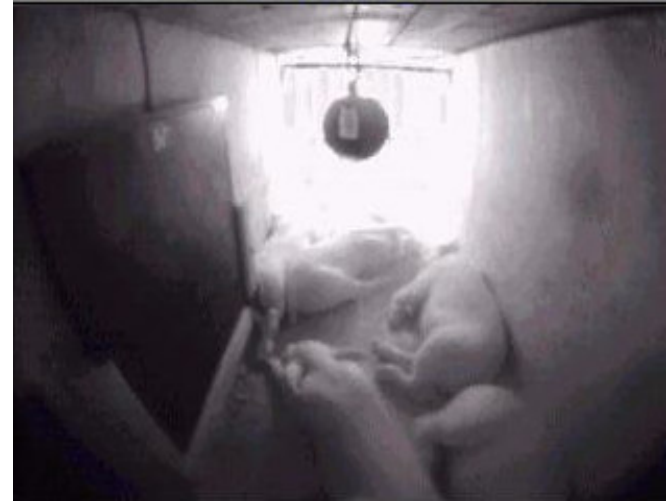

(a)

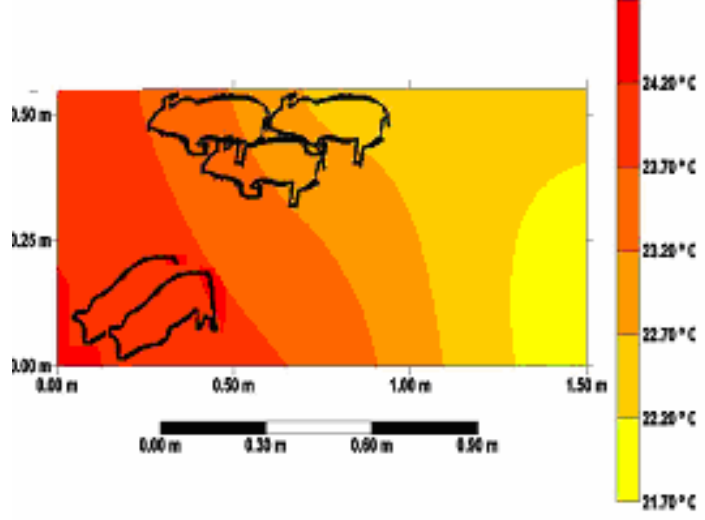

(b)

FIGURA 10. Imagem captada (a) e representação das isotermas (b) representando o perfil de distribuição dos animais, para o abrigo equipado com lâmpada incandescente, para as 8 horas.

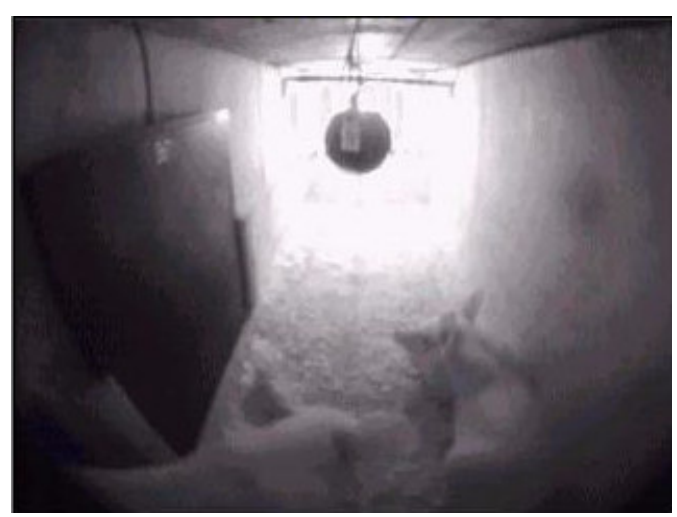

(a)

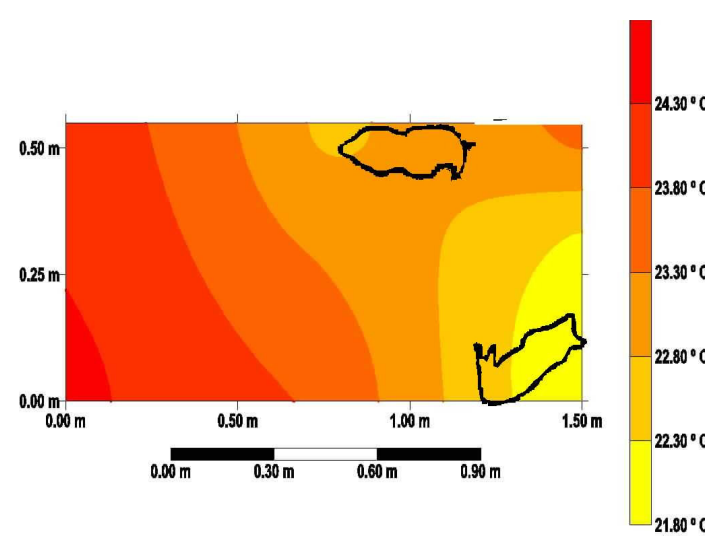

(b)

FIGURA 11. Imagem captada (a) e representação das isotermas (b) representando o perfil de distribuição dos animais, para o abrigo equipado com lâmpada incandescente, para as 16 horas.

\section{CONCLUSÕES}

Referindo-se ao perfil de distribuição dos leitões no interior dos abrigos, verifica-se, em geral, que, para todos os tratamentos avaliados, os animais apresentaram a tendência de buscar pontos mais próximos da fonte de calor ou as faixas de maior temperatura do piso no horário mais frio, sendo que, para o horário mais quente, o padrão de distribuição se inverteu, ou seja, os animais buscaram regiões do piso que apresentavam faixas de menor temperatura e mais distantes da fonte de calor.

A criação das isotermas por meio da análise de imagem permitiu analisar o comportamento dos animais em função das variáveis ambientais, indicando o piso térmico como o mais eficiente nas trocas de calor sensível por condução (contato), promovendo melhor condição de conforto aos animais. 


\section{REFERÊNCIAS BIBLIOGRÁFICAS}

ALBRIGHT, L.D. Environment control for animals and plants. St. Joseph: American Society of Agricultural Engineers, 1990. 453 p. (ASAE Textbook, 4)

CURTIS, S.E. Environmental manegement in animal agriculture. Ames: State University Press, 1983. $409 \mathrm{p}$.

MOUNT, L.E. The climate physiology of the pig. Baltimore: Williams \& Welkins, 1968. 271 p.

MOURA, D.J.; NÄÄS, I.A.; SILVA, I.J.O.; SEVEGNANI, K.B.; CORRIA, M.E. The use entalpy as a thermal comfort index. In: LIVESTICK ENVIRONMENT, 5., 1997, St. Joseph. Proceedings... St. Joseph: American Society of Agricultural Engineers, 1997. v.1, p.242-8.

ROSSI, L.A.; CARDOSO, P.E.R.; BERALDO, A.L. Desempenho de placas de argamassa de cimento e casca de arroz aquecidas por resistência elétrica. In: CONGRESSO BRASILEIRO DE

ENGENHARIA AGRÍCOLA, 31., 2002, Salvador. Anais... Salvador: Sociedade Brasielira de Engenharia Agrícola, 2002. 1 CD ROM.

SAS INSTITUTE. Statistical analysis system: realease 6.08, (software). Cary, 1992. 620 p.

SILVA, I.J.O. Qualidade do ambiente e instalações na produção industrial de suínos. In: SIMPÓSIO INTERNACIONAL DE SUINOCULTURA, 3., 1999, São Paulo. Anais... São Paulo: Gessuli, 1999. p.108-325.

XIN, H.; SHAO, J. Real-time assessment of swine thermal comfort by computer vision. In: WORLD CONGRESS OF COMPUTERS IN AGRICULTURE AND NATURAL RESOURCES, 2., 2002, Foz do Iguaçu. Proceedings... Foz do Iguaçu: American Society of Agricultural Engineers, 2002. p.362-9. 